\section{REVISTA KINESIS}

Dossiê CEFD 50 anos
UFSM

Rev. Kinesis, Santa Maria, RS, Dossiê CEFD 50 anos, p.01-11, 2020

DOI: https://doi.org/10.5902/2316546448525

\title{
Testemunho de um professor alemão visitante no CEFD/UFSM: Jürgen Dieckert
}

A visiting German professor testimony at CEFD/UFSM: Jürgen Dieckert

Testimonio de un profesor alemán visitante en el CEFD/UFSM: Jürgen Dieckert

Janice Zarpellon Mazo ${ }^{\mathrm{I}}$, Raquel Valente de Oliveira ${ }^{\mathrm{II}}$

Figura 1 - Professor Doutor Jürgen Dieckert

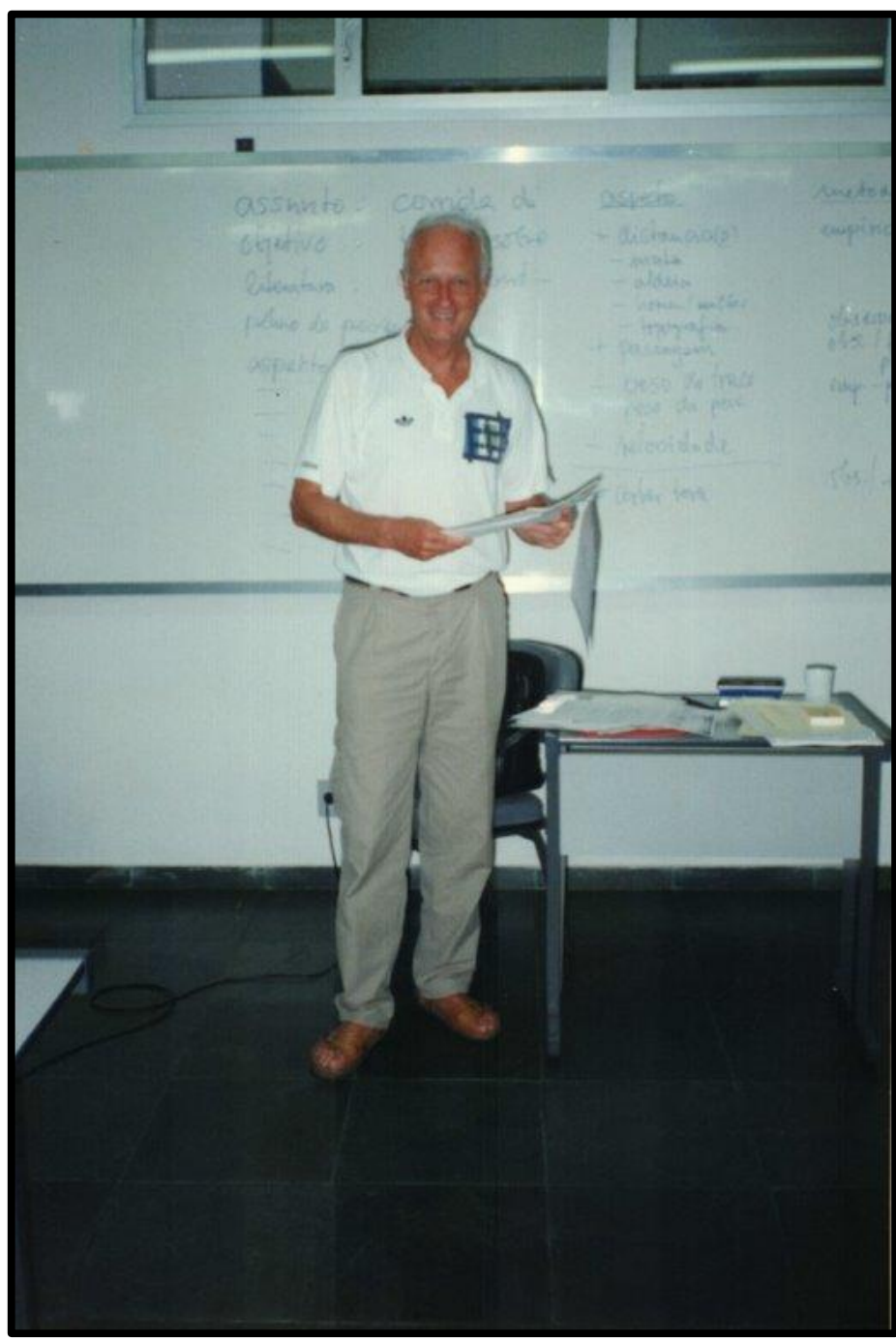

Fonte: Acervo pessoal da Professora Doutora Janice Zarpellon Mazo

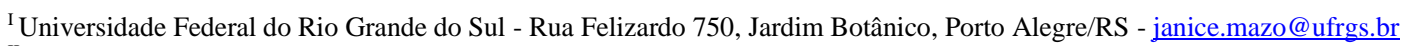

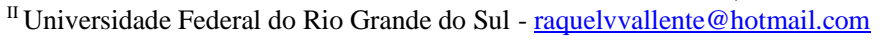




\title{
Resumo
}

Diante da comemoração dos 50 anos da instauração do Centro de Educação Física e Desportos (CEFD) da Universidade Federal de Santa Maria (UFSM), faz-se necessário rememorar acontecimentos e personagens, a fim de reunir indícios para refletir acerca das distintas versões históricas sobre o CEFD e a formação de professoras(es) na área da Educação Física, oferecida pela instituição ao longo de cinco décadas. Dentre essas(es) personagens, fazemos referência a Jürgen Alfred Fritz Dieckert, professor alemão visitante no curso de Mestrado em Ciência do Movimento Humano do CEFD, entre os anos de 1980 e 1983. Apresentamos uma entrevista, guiada pelos pressupostos teóricometodológicos da História Oral, realizada com o professor Jürgen Dieckert sobre o período em que atuou como professor visitante no CEFD/UFSM. Destacam-se informações referentes à comunidade acadêmica do CEFD e à concepção de Educação Física inerente à época.

Palavras-chave: História da Educação Física; Formação de professoras(es); História Oral

\begin{abstract}
Given the celebration of 50th anniversary of the establishment of Physical Education and Sports Center (CEFD) of Federal University of Santa Maria (UFSM), it is necessary to recall events and characters, in order to gather evidence to reflect on the different historical versions about CEFD and the teacher qualification in the Physical Education field offered by the institution over five decades. Among these characters, we refer to Jürgen Alfred Fritz Dieckert, visiting German professor in Human Movement Science Master's course at CEFD, between the years 1980 and 1983. We present an interview, guided by the theoretical and methodological assumptions of Oral History, conducted with Professor Jürgen Dieckert on the period when he served as a visiting professor at CEFD/UFSM. Information regarding CEFD academic community and the concept of Physical Education inherent at the time is highlighted.
\end{abstract}

Keywords: Physical Education History; Teacher qualification; Oral History

\section{Resumen}

Dada la celebración del 50 aniversario de la creación del Centro de Educación Física y Deportes (CEFD) de la Universidad Federal de Santa María (UFSM), es necesario recordar eventos y personajes, a fin de reunir evidencias para reflexionar sobre las diferentes versiones históricas del CEFD y la capacitación de los docentes en el área de la Educación Física ofrecida por la institución durante cinco décadas. Entre estos personajes, nos referimos a Jürgen Alfred Fritz Dieckert, profesor visitante alemán en el curso de Máster en Ciencia del Movimiento Humano en el CEFD, entre los años 1980 y 1983. Presentamos una entrevista, guiada por los supuestos teóricos-metodológicos de la Historia Oral, realizada con el profesor Jürgen Dieckert sobre el período en que él ha actuado como profesor visitante en CEFD/UFSM. Se destaca la información sobre la comunidad académica del CEFD y el concepto de educación física inherente en ese momento histórico.

Palabras clave: Historia de la Educación Física; Formación del profesorado; Historia Oral

\section{Considerações Iniciais}

No delinear do percurso histórico do Centro de Educação Física e Desportos da Universidade Federal de Santa Maria (CEFD/UFSM), identificamos a presença de professores visitantes oriundos da Alemanha em certos períodos. Alguns destes professores alemães foram convidados a integrar o corpo 
docente do curso de Mestrado em Ciência do Movimento Humano do CEFD, cuja criação ocorreu no ano de 1979. Cabe mencionar que, na época, alguns professores do CEFD estavam cursando mestrado no exterior, em busca de qualificação, impulsionados pela Coordenação de Aperfeiçoamento de Pessoal de Nível Superior (CAPES), por meio de convênio com universidades americanas (MAZO, 1992; 1993).

Dentre os professores alemães visitantes, destacamos a expressiva atuação de Jürgen Alfred Fritz Dieckert, entre os anos de 1980 e 1983 (TAFFAREL, 2015), no recém implantado curso de Mestrado em Ciência do Movimento Humano do CEFD. Advindo da Escola Superior de Esporte da República Federal da Alemanha, o professor Dieckert veio para o Brasil por meio do convênio entre o Serviço Alemão de Intercâmbio Acadêmico (DAAD), a Coordenação de Aperfeiçoamento de Pessoal de Nível Superior (CAPES) e o Conselho Nacional de Desenvolvimento Científico e Tecnológico (CNPq). O convênio foi efetivado com a finalidade de estabelecer um núcleo pedagógico na área da Educação Física da UFSM e, de tal modo, contribuir para a consolidação do curso de mestrado no CEFD (MAZO, 1997).

Em 1980, seu primeiro ano no CEFD/UFSM, o professor Dieckert implantou a proposta denominada "Esporte para Todos", conhecida pela sigla EPT, a qual tinha por intuito oferecer práticas esportivas destinadas ao lazer e à recreação. O professor Dieckert apregoava que a Educação Física escolar brasileira deveria sofrer uma significativa transformação e adotar o esporte de alto rendimento como base para a formação dos alunos (MAZO, 1997; ROSA, 2017). No ano seguinte, em 1981, assumiu a coordenação do programa MEXA-SE, contemplado pela campanha do "Esporte para Todos", o qual oferecia práticas de futebol, ginástica geral, ginástica rítmica, recreação aquática e voleibol para professores(as) e técnicos(as) da UFSM (MAZO, 1997). Também promoveu atividades voltadas à formação continuada para professores(as) de escolas municipais e da rede estadual de ensino do Rio Grande do Sul. No entanto, as ações desenvolvidas pelo professor Dieckert não se restringiram ao estado sul-rio-grandense, trazendo, também, significativas contribuições à Educação Física brasileira por intermédio de suas pesquisas científicas, dos cursos, das palestras e das aulas ministradas em diversas regiões do país (TAFFAREL, 2015).

Nesta perspectiva, o presente estudo tem como objetivo apresentar uma entrevista realizada com o professor Jürgen Alfred Fritz Dieckert, relativa à sua trajetória acadêmica e profissional, sobre o período em que atuou como professor visitante no CEFD/UFSM (1980-1983). Esta entrevista foi realizada pela professora doutora Janice Zarpellon Mazo, no dia quatro de setembro de 1995, na cidade de Vitória/ES, durante um evento acadêmico. Vale salientar que a entrevista teve o propósito inicial de coletar informações para a elaboração do livro comemorativo dos 25 anos (1970-1995) do CEFD/UFSM, o qual teve a 
publicação viabilizada pela iniciativa do professor Luiz Celso Giacomini, assim como o lançamento do livro em festividade ocorrida na UFSM.

$\mathrm{Na}$ época, buscou-se conduzir a entrevista com o professor Dieckert ancorando-se no referencial teórico-metodológico da História Oral (ALBERTI, 2008; FERREIRA; AMADO, 2006), enquanto uma metodologia de composição de fontes orais. Considera-se que a História Oral traz uma contribuição fundamental para os estudos históricos, pois torna possível acessar "histórias dentro da história" a partir dos testemunhos de personagens. Ao compartilharmos a entrevista realizada com o professor Dieckert, após 25 anos da sua produção, quando o CEFD/UFSM completa 50 anos de fundação (1970-2020), esperamos contribuir para pesquisas que ampliem as possibilidades de interpretação da história deste Centro de ensino e da Educação Física brasileira.

\section{Início do percurso docente no Brasil}

O professor Dieckert relatou: No ano de 1977, tive a possibilidade de fazer um curso aqui no Brasil, com tradutora, 15 dias em São Paulo/SP e 15 dias em Belo Horizonte/MG. Nesta ocasião, não me adaptei. Apesar de estar aprendendo a língua e conhecendo a cultura, ficava sempre dependendo da tradutora. Ela se comunicava com os alunos e eu não gostei, porque percebi que muitas coisas que eu dei de informações nas aulas foram "voando em cima das cabeças” dos alunos. A expressão entre aspas sugere a percepção do professor Dieckert diante da situação, quando afirmou: Eu não consegui entrar na mentalidade, na capacidade das pessoas que assistiam, dos professores de Educação Física das escolas. Por isso, eu decidi voltar para a Alemanha e aprender um pouco, 50 palavras ou mais [da língua portuguesa] em uma escola privada, na minha cidade de origem.

No ano de 1978, eu voltei e acabei, nessa ocasião, dando um curso em Goiânia/GO e, mais 15 dias, em Fortaleza/CE. Eu já conseguia me integrar na mentalidade brasileira um pouco melhor. Contudo, ainda me comunicava através de uma tradutora. Na última aula em Fortaleza, eu decidi não usar mais a tradutora, mas me comunicar através da expressão corporal e através das 50 palavras que havia aprendido. De uma maneira incrível, todo mundo gostou. Claramente, não depende de mim, depende dos brasileiros, das brasileiras, porque eles têm esse calor humano que eu gostei. É o que eu amo aqui no Brasil.

Nesta ocasião, o professor Haimo Fensterseifer [que falava o idioma alemão] estava como avaliador do meu trabalho. Ele estava ajudando a Secretaria de Educação (SEED), do Ministério da Educação (MEC), situada em Brasília. Ele me convidou, dizendo: "Dieckert, eu percebi como tu queres 
entrar na "cabeça" dos alunos. Tu queres te adaptar, integrar. Não queres trabalhar em Santa Maria comigo?" Eu olhei para minha mulher, minha esposa, e ela achou um pouco dificil, como as mulheres acham, às vezes. Mas, voltando, nós decidimos aceitar esse convite. No ano de 1980 até 1983, eu trabalhei no CEFD, em Santa Maria, como professor visitante.

Sobre as dificuldades enfrentadas com relação à língua portuguesa, o professor Dieckert avaliou: Aprendi o português em um curso especial de um mês e, chegando a Santa Maria, comecei a dar aulas em português. Foi um pouco difícil, mas, através da expressão corporal, eu consegui. Aprendi muito bem o português para estabelecer a comunicação. Não falo muito bem, mas acho que dá para me entender. Além disso, ele pondera: Acontece "essa coisa" que vale para a vida, a "empatia", se tem uma emoção positiva entre o professor e os alunos. Eu acho uma língua reduzida, uma língua simples e eu aprendi para minha vida como explicar coisas complicadas de uma maneira simples. Segue seu relato afirmando: Percebi nos meus colegas, na Alemanha e no Brasil, como eles complicam as coisas simples através da língua. Eu vim semianalfabeto, mas achei outro caminho, simplificando, analisando o problema.

\section{Os alunos do CEFD/UFSM: primeiras impressões do professor Dieckert}

Primeiramente, eu trabalhei no curso de mestrado. Sobre isso, Dieckert descreve as características dos alunos: Todos os alunos não foram “bem” alunos, mas, professores de Educação Física, sem mestrado, adultos de 30 e poucos anos. Por isso, a comunicação entre um alemão de 40 e poucos anos, nesta época, com os colegas de 30 e poucos anos, ocorreu muito bem. Mas, em seguida, eu percebi que a base teórica dos colegas não foi muito ampla, não foi muito grande, porque eles receberam, nestas épocas, só através da graduação, um nível que não corresponde ao nível que nós temos na Alemanha. Eu percebi que eles nunca escreveram um "livrinho", uma dissertação, uma tese ou qualquer outro pensamento lógico. Eles não foram bem preparados para isso.

No entanto, não era uma falha dos professores, mas, sim, uma falha na educação básica, nas escolas, porque tem que aprender a "usar a cabeça", não só a boca. E o sistema que percebi aqui no Brasil, na escola e nas universidades, é informar para avaliar se os alunos não esqueceram a informação, para testar a capacidade da memória e não a capacidade de pensar ou a capacidade de desenvolver mais conhecimento. Por isso, eu tive um "crash”, uma situação de conflito com meus colegas e alunos quando pude expressar um pensamento argumentativo. Eu pedi aos meus colegas e alunos para escreverem como eles devem preparar um texto para argumentar. Eu dei um exemplo: "O reitor da sua universidade o chama e você tem que explicar por que a Educação Física é "uma coisa" essencial na escola e, também, na 
formação dos professores. Por favor, escrevam esse tipo de argumentação." Achei uma situação bem normal, da vida e da necessidade de justificar o que eles fazem. Dos 15 ou mais professores, 13 se recusaram a escrever. Somente dois fizeram. Os outros acharam que era uma tarefa, que era uma obrigação. Incrível! Eles não aceitaram; foi um choque!

Neste momento, eu percebi que eles não sabem pensar, no sentido de pensar logicamente, não pensam como escrever. Assim, eu pensei: "Se você quer escrever uma dissertação no final do processo, você precisa "treinar” um pensamento argumentativo e lógico”. Depois, a situação melhorou. Foi um conflito da vida. Foi um conflito! De repente, eles aprenderam que devem trabalhar de uma maneira diferente. Eu dei sempre "impulsos" para pensar de forma autônoma, não receber informações prontas. Nesse momento, nós treinamos como confeccionar um pensamento lógico, qual seria a problematização de um problema, como analisar, operacionalizar o problema. Depois, como organizar os elementos do problema, os elementos básicos, os elementos mais periféricos, como estruturar e como resolver o problema através das novas ideias. Nós desenvolvemos um tipo de pensamento, de uma cultura de pensamento. Os alunos que não quiseram foram trabalhar na Biomecânica e na Fisiologia, não quiseram desenvolver esse tipo de pensamento. Já os alunos da Filosofia, da Filosofia do Homem, da Pedagogia e da Sociologia, que ficavam comigo, tentando fazer a dissertação de mestrado, foram e estavam preparados para esse tipo de pensamento.

Eu percebi que, em Santa Maria, se desenvolveu dois grupos: um grupo de pensadores comigo e um grupo de cientistas empíricos, que tentaram fazer pesquisas que já haviam sido feitas lá nos Estados Unidos da América (EUA), com uma metodologia exata, com uma metodologia já feita, só aplicando para o povo brasileiro. Mas, nós, das Ciências Humanas e Sociais, recebemos a tarefa não só de determinar bem o problema, mas, também, de desenvolver uma metodologia específica de como resolver o problema. Eu acho que o meu trabalho foi muito bem nesse sentido. Todos que fizeram mestrado comigo fizeram de uma maneira muito boa: o trabalho da Celi Taffarel, eu fiz a publicação [...], e outras publicações dos alunos também. Agora, pensando: uma aluna minha foi duas vezes presidente [trata-se da presidência do Colégio Brasileiro de Ciências do Esporte, cuja sigla é CBCE] e, por exemplo, o Elenor Kunz, vicepresidente de todos os professores da Educação Física do Brasil [novamente se refere a uma posição ocupada na diretoria do CBCE]. Eu acho que eles aprenderam a "usar a cabeça” para pensar e não usavam só os trabalhos do Haimo Fensterseifer e dos demais colegas. Por isso, eu convidei o Haimo para fazer doutorado no meu país [Alemanha] quando retornei em 1983. Assim, também ajudei um brasileiro a ser doutor para voltar e para desenvolver essa "cultura da cabeça” na Educação Física. 
Neste momento, vamos abrir um parêntese para compartilhar as lembranças da autora, Janice Mazo, sobre o professor Haimo Fensterseifer, acionadas pelo relato do professor Dieckert. Lembro que, após retornar do curso de doutorado na Alemanha, o professor Haimo ministrou aulas no curso de Mestrado em Ciência do Movimento Humano do CEFD/UFSM, onde começou a orientar alunos(as). Na época, tive a oportunidade de assistir as aulas do curso de mestrado, na condição de aluna ouvinte, após pedir "autorização" ao professor Haimo. Mesmo tendo concluído o curso de Licenciatura em Educação Física, e já atuando como professora em uma escola particular de Santa Maria, eu frequentava o CEFD/UFSM, pois era aluna do curso de especialização em Técnica Desportiva - Voleibol. Em seguida à conclusão deste curso, ingressei no curso de Especialização em Pesquisa Curricular a convite do professor Haimo, organizador e professor do curso. Durante o curso de especialização, estudamos teorias do currículo e, em alguns momentos, o professor Haimo referia sobre o currículo, a educação e a formação de professores(as). Ou seja, questões relativas a seu doutorado na Alemanha e a uma de suas referências no modo de pensar a Educação Física: o professor Dieckert.

Apresentada esta versão das vivências da professora Janice Mazo no CEFD/UFSM, voltamos ao relato do professor Dieckert. Ele faz uma análise da sua atuação: $O$ meu trabalho, aqui no Brasil, foi um trabalho muito amplo, pois não trabalhei somente em Santa Maria. Dei muitos cursos em todo o País, muitas vezes, cursos de criatividade, porque ser criativo é uma "cultura da cabeça”, fazer coisas que antes ninguém fez. Eu percebi que, nas aulas de Educação Física e nas escolas, os alunos eram, por vezes, “xerox" do professor. Eles imitavam o professor, faziam pouco e ficaram muito marginalizados. Eles mantêm influência. Infelizmente, eu conheço brasileiros que falam de índio como "bicho do mato", mas, eu acho que eles nunca ficaram abertos para respeitar a cultura brasileira e, desta maneira, uma pessoa se fecha. Pensando só em si, nunca irá aprender, nunca poderá se desenvolver e contribuir para o desenvolvimento.

Finalizando, gostaria de dizer que aprendi muito mais do que ensinei aqui no Brasil, porque ensinar tem uma condição básica. Primeiramente, aprendi a língua, aprendi a cultura, aprendi muita coisa da vida e, através desse aprender e entender, eu fiquei na situação de ensinar. Por isso, 18 anos no Brasil, um terço da minha vida, deu muito "impulso" para minha vida e deu, também, um “impulso” para o Brasil. Estou feliz!

\section{Os professores do CEFD/UFSM: primeiras impressões do professor Dieckert}


Ao chegar a Santa Maria, conta o professor Dieckert: Eu encontrei o CEFD no nível de graduação, como todas as universidades do Brasil, com uma formação mais técnica, uma formação orientada ao treinamento de vôlei, de atletismo e de natação, mas não adaptada à realidade brasileira. Fazer salto em altura de "fosbury-flop" não vale se uma escola primária não tem instalações para fazer isso. O que vale a natação e os diferentes estilos se os alunos da escola não têm água para nadar e não têm piscina? O que vale um tipo de Ginástica Olímpica, com aparelhos sofisticados, se não têm esses aparelhos na escola? Com isso, eu percebi, como em todas as formações no Brasil, que não havia Educação Física adaptada à realidade. A minha tentativa foi, dentro do curso de mestrado, dar "impulsos". Temos que mudar o currículo para dar mais apoio.

Nota-se que um dos "impulsos" ecoou na atuação da professora Celi Taffarel, que, residindo na cidade de Recife/PE, buscou introduzir um novo currículo adaptado à realidade, porque a realidade de Recife era pior que a de Santa Maria. Por isso, tentei dar "impulsos" no sentido do "Esporte para Todos". Fizemos muita coisa lá. Nós formamos um grupo de recreação e esporte para todos. Também, tentamos convencer a comunidade a desenvolver parques de lazer e esporte. Escrevi um livro para a SEED/MEC sobre esporte para todos: "Parque de Lazer e de Esporte para Todos". Nós fizemos festas de esporte de alto nivvel, que fica como base da formação. Avaliando, acho que dei muitos "impulsos”, mas os docentes foram divididos entre os mais técnicos e entre os que quiseram "pensar" de uma maneira diferente.

Saindo de Santa Maria, depois do ano de 1984, quando voltei para a Alemanha, alguns me disseram que não funcionou muito bem a teoria do "Esporte para Todos" em Santa Maria. Não sei por que, eles direcionaram a teoria mais no sentido de uma formação técnica, de uma formação das disciplinas do esporte. Eu não sou contra as disciplinas do esporte, mas, eu sou contra um currículo que só dá ênfase a essas disciplinas. Eu tentei "entrar na cabeça” dos colegas: a Educação Física nas escolas tem a tarefa de educar para a vida fora da escola. Então, o que é educar para fora da escola? Através do sistema de autonomia dos alunos para auto-organização. O professor da universidade tem que educar o aluno na formação, na Educação Física, para a autonomia, para que ele possa dar essa autonomia aos alunos que estão na escola. Mas, esse caminho não funcionou!

Eu acho que o desenvolvimento do aluno e do cientista não é fazer "xerox", mas, desenvolver isso de uma maneira autônoma, de uma maneira bem desenvolvida, com criatividade. Por isso, eu tentei usar a força que cada um de nós tem. Nós chamamos de criatividade, um pouco mais que a inteligência que nós recebemos dos EUA. Eles estão testando a inteligência, mas eles perdem uma capacidade da "cabeça". Nós chamamos de criatividade. Eu ministrei esse tipo de curso e percebi que ainda faltava muita literatura aqui no Brasil. 
Juntamente com uma editora, montei um livro técnico, sete livros de fundamentação, 11 livros ou mais sobre metodologia do vôlei, metodologia [...], mas, também, sobre motricidade, sobre filosofia da Educação Física, etc. Pessoalmente, como professor na UFSM e, também, nos cursos que ministrei, eu tentei multiplicar conhecimentos através da literatura. Assim, o Ministério me chamou para ser membro da Coordenadoria Pedagógica (COPED), junto com um grupo de cinco ou seis pessoas para desenvolver a pesquisa aqui no Brasil. Eu fui o único estrangeiro. Eu acho que dei muitos "impulsos” para melhorar a situação aqui no Brasil, porque eu já aprendi muito como funciona, quais são as deficiências, e nós desenvolvemos um plano. Grande parte do plano foi feito na minha mesa. Claramente, eu gosto muito de todos os elementos desse grupo de brasileiros, mas, o caminho feito foi mais o caminho do alemão.

Voltando para a Alemanha, eu não terminei a minha colaboração com o Brasil. Tive doutorandos, sempre em contato com o Brasil. Eu ministrei cursos aqui no Brasil. Muitos cursos em Recife, porque aprendi que Santa Maria/RS, São Paulo/SP e Rio de Janeiro/RJ já eram bem desenvolvidos, mas, a região do Nordeste ainda tinha muitos problemas. Por isso, eu fiz uma grande amizade com a Celi Taffarel, como professora, lá em Recife, e nós desenvolvemos um núcleo da Educação Física. Também, no ano de 1984, eu ministrei um curso de 15 dias em Santa Maria, do dia 10 de março até o dia 23 de março. Em suma, eu visitei várias vezes Santa Maria para ministrar aulas e palestras, durante a década de 1980.

Gostaria de dizer que consegui participar e contribuir com o desenvolvimento de uma cultura da Educação Física e, hoje, percebo que tem uma geração de professores e professoras que estão muito mais no caminho que eu quis [...], muito mais do que 15 anos ou 10 anos atrás. Por isso, tenho um 'feeling'! Eu me sinto muito bem sabendo que todo o trabalho que tentei fazer aqui teve frutos. Através dos meus amigos e colegas, como Celi Taffarel, Valter Bracht, Elenor Kunz e outros que receberam "impulsos” de mim, eu tenho a impressão de que o Brasil, na matéria da Educação Física, vai crescer. Por isso, eu vou sair do País na semana que vem [setembro de 1995] com a certeza que foi um trabalho que valeu a pena, não um turismo.

Também, gostaria de dizer que, quando o primeiro brasileiro disse pra mim: "Dieckert, eu tenho a impressão de que tu não és mais alemão, tu já és brasileiro”, eu fiquei muito feliz. Quando recebi esta fala e quando li em cartas e em um livro que "o Dieckert nasceu como alemão, mas ele tem um coração brasileiro", eu me senti muito feliz. Nesse sentido, valeu todo o trabalho! Na minha época, aprendi como antropólogo, vivendo com uma tribo indígena por mais de um ano, que fiz pesquisa sobre a cultura lúdica do movimento, uma contribuição para o país, para respeitar melhor a cultura própria do país. Não tem a cultura brasileira, é mais uma cultura importada dos EUA e da Europa. Mas, têm duas culturas próprias do movimento brasileiro: a cultura negra, pensando em danças, pensando em capoeira, toda a música e o 
movimento que nós recebemos desta influência da África; e cultura do índio. Infelizmente, há poucos brasileiros que trabalham nesse campo para conhecer um pouco melhor das tribos indígenas.

\section{Considerações Finais}

O texto apresentado evidencia as transformações e contribuições suscitadas pelo professor Jürgen Dieckert à área da Educação Física brasileira, assim como aos cursos de graduação e pós-graduação do CEFD/UFSM no ínterim de suas composições históricas. Nesse sentido, este estudo teve por objetivo apresentar uma entrevista realizada com o professor Jürgen Alfred Fritz Dieckert, relativa à sua trajetória acadêmica e profissional, sobre o período em que atuou como professor visitante no CEFD/UFSM (19801983). Com essa narrativa historiográfica, foi possível compreendermos diversas informações sobre alunos e professores do CEFD e sobre a concepção de Educação Física inerente à época. Tais informações, em seu conjunto, nos dão indícios sobre as representações e as práticas culturais que foram produzidas no período investigado, tanto pelo professor Jürgen Dieckert enquanto docente e pesquisador, quanto pelos demais agentes envolvidos, não somente na história do CEFD, mas em outros cenários da Educação Física.

Por meio do depoimento do professor Dieckert, evidenciamos que os docentes e alunos que tinham seus interesses acadêmicos voltados às Ciências Humanas e Sociais não estavam preparados para desempenhar o papel de pesquisadores da área, tampouco para refletir acerca de sua práxis, salvo exceções assinaladas na entrevista apresentada. Durante o período em que atuou no Brasil, Dieckert elucida que a Educação Física era composta por profissionais que se dedicavam à prática, ao "saber fazer" e a uma formação mais técnica. Em uma de suas falas, Dieckert destaca que "os docentes foram divididos entre os mais técnicos e entre os que quiseram "pensar" de uma maneira diferente". Alicerçadas nesta narrativa, assim como na literatura científica disponível sobre os princípios didático-pedagógicos da área, nos deparamos com indícios históricos que dizem respeito à concepção de Educação Física que prevalecia nas décadas de 1980 e 1990. A partir de tais conhecimentos, podemos melhor compreender a história da Educação Física, bem como as rupturas e (des)continuidades pelas quais a área perpassou ao longo dos anos.

Com o trabalho realizado no curso de mestrado do CEFD e nos cursos ministrados em eventos/palestras em outras regiões do País, Dieckert veio a corroborar de forma significativa com a área pedagógica da Educação Física, tanto no CEFD, quanto nos demais locais em que atuou posteriormente. Assim como mencionou em alguns trechos de seu depoimento oral, Dieckert preocupava-se com a capacidade do professor/aluno construir e difundir conhecimentos de forma autônoma e plural, suscitando 
significados para além daqueles que predominavam na Educação Física brasileira da época, isto é, pautados na formação técnica e esportivista. Ressaltamos que o trabalho e a dedicação do professor Jürgen Dieckert, juntamente ao CEFD/UFSM, colaboraram não apenas para o crescimento e expansão do curso de Mestrado do Programa de Pós-Graduação em Ciência do Movimento Humano, mas para a abertura do curso de doutorado anos mais tarde, em 1990.

\section{Referências}

ALBERTI, Verena. Fontes Orais: histórias dentro da história. In: PINSKY, Carla B. (Org.). Fontes Históricas. 2. ed. São Paulo: Contexto, 2008. p. 155-202.

FERREIRA, Marieta M.; AMADO, Janaína. (Orgs.). Usos e abusos da História Oral. 8. ed. Rio de Janeiro: Editora FGV, 2006.

MAZO, Janice Z. A história do Centro de Educação Física e Desportos da Universidade Federal de Santa Maria/UFSM: 25 anos. Santa Maria: UFSM, CEFD, 1997.

O Centro de Educação Física da Universidade Federal de Santa Maria: percorrendo os caminhos de sua criação. 1993. 152 f. Dissertação (Mestrado em Ciência do Movimento Humano) Universidade Federal de Santa Maria, Santa Maria, 1993.

A história do Centro de Educação Física e Desportos da Universidade Federal de Santa Maria: um relato cronológico. Kinesis, Santa Maria, n. 10, p. 19-47, jul./dez. 1992.

ROSA, Juliano M. O CEFD/UFSM na atribuição de sentidos à Educação Física Escolar entre 1970 e 2004. 2017. 262 f. Tese (Doutorado em Educação) - Universidade Federal de Santa Maria, Santa Maria, 2017.

TAFFAREL, Celi Z. Homenagem Jürgen Dieckert: Professor Honorífico da UFBA. Motrivivência, Florianópolis, v. 27, n. 45, p. 298-300, set. 2015.

\section{Como citar este artigo}

MAZO, J. Z.; OLIVEIRA, R. V. Testemunho de um professor alemão visitante do CEFD/UFSM: Jürgen Dieckert. Revista Kinesis, Santa Maria, v. 38, p.01-11, 2020.

* O presente trabalho não contou com apoio financeiro de nenhuma natureza para sua realização. 